\title{
Maurizio Gatti, Littérature amérindienne du Québec: écrits de langue française
}

\section{Veronica Cappellari}

\section{(2) OpenEdition}

1 Journals

\section{Edizione digitale}

URL: http://journals.openedition.org/studifrancesi/33787

DOI: 10.4000/studifrancesi.33787

ISSN: 2421-5856

\section{Editore}

Rosenberg \& Sellier

\section{Edizione cartacea}

Data di pubblicazione: 1 décembre 2005

Paginazione: 684

ISSN: 0039-2944

\section{Notizia bibliografica digitale}

Veronica Cappellari, «Maurizio Gatti, Littérature amérindienne du Québec: écrits de langue française»,

Studi Francesi [Online], 147 (XLX | III) | 2005, online dal 30 novembre 2015, consultato il 19 avril 2021.

URL: http://journals.openedition.org/studifrancesi/33787 ; DOI: https://doi.org/10.4000/studifrancesi. 33787

Questo documento è stato generato automaticamente il 19 avril 2021.

\section{(c) (1)}

Studi Francesi è distribuita con Licenza Creative Commons Attribuzione - Non commerciale - Non opere derivate 4.0 Internazionale. 


\title{
Maurizio Gatti, Littérature amérindienne du Québec: écrits de langue française
}

\author{
Veronica Cappellari
}

\section{NOTIZIA}

MAURIZIO GATTI, Littérature amérindienne du Québec: écrits de langue française, préface de Robert LALONDE, Montréal, Éditions Hurtubise HMH, 2004, pp. 271.

Littérature amérindienne du Québec segna un momento importante nella storia delle letterature francofone. Per la prima volta, infatti, viene pubblicata una raccolta di testi contemporanei di scrittori autoctoni del Québec che hanno scelto di esprimersi in lingua francese. L'antologia, frutto dell'appassionata e minuziosa ricerca condotta in tutte le comunità native del Québec da Maurizio Gatti, giovane ricercatore di origine italiana, presenta un panorama ricco ed elaborato della letteratura amerindiana, costituito da settantatre testi, molti dei quali inediti, composti da ventinove autori appartenenti alle undici nazioni amerindiane presenti in Québec. All'interno dell'antologia non trovano spazio, tuttavia, alcune particolari forme letterarie come la canzone ed il saggio. L'autore, nell'introduzione, ne spiega i motivi: la canzone, in quanto è scritta in differenti lingue amerindiane difficili da capire; il saggio perché è un genere che, a suo avviso, sarebbe risultato una "stonatura" all'interno di un'antologia dedicata alla narrativa, all'autobiografia, alla poesia ed al teatro. Come evidenzia Maurizio Gatti, la letteratura amerindiana del Québec evolve da una tradizione orale e raggiunge il suo maggior sviluppo a partire dalla seconda metà del XX secolo. Essa eredita il traumatico rapporto di convivenza instauratosi tra europei e amerindiani, intorno al 1800, terminato con il confinamento di questi ultimi nelle riserve. Questo fenomeno ha causato non pochi problemi di identità al popolo amerindiano, il quale ha cercato, attraverso la scrittura, di esprimere la propria sofferenza per la libertà negata. 
Il recupero della tradizione e di quei valori offuscati dalla cultura occidentale diviene così la direttrice fondamentale della ricerca di una specifica identità amerindiana.

2 Nell'antologia di Maurizio Gatti figurano, come si è detto, varie forme di creazione letteraria - contes et légendes, poèmes, estratti di romans e di pièces théâtrales, récits et témoignages - trattate, ognuna, in una particolare e distinta sezione dell'antologia. Fra gli autori presenti nell'opera si annoverano Christine Sioui Wawanoloath e André Dudemaine per contes et légendes; Éléonore Sioui, Rita Mestokosho, Silvie-Anne SiouiTrudel e Romeo Saganash per i poèmes; Bernard Assiniwi e Michel Noël per il roman; Jean-Marc Niquay e i già sopra citati Bernard Assiniwi e Christine Sioui Wawanoloath per il théâtre; ed infine Georges E. Sioui e Richard Kistabish per récits et témoignages. L'opera si conclude con i Profils d'auteurs, dettagliate e particolareggiate schede biografiche dei singoli scrittori presi in esame, che costituiranno sicuramente un valido strumento di lavoro per tutti coloro che vorranno intraprendere ricerche in questo campo. Littérature amérindienne du Québec: écrits de langue française fornisce complessivamente agli studiosi, ai ricercatori o semplicemente a tutti coloro che vogliono scoprire questa giovane letteratura, uno stimolante ed originale sussidio volto a diffonderne e a valorizzarne l'apporto culturale, sociale e spirituale. È questo un grande merito dello studioso italiano, come riconosce il noto scrittore di origine mohawk Robert Lalonde nella prefazione all'antologia di Gatti: "il fallait bien arriver d'Italie pour ouvrir d'abord une oreille impartiale, puis un œil intègre, neuf, sur ces mots qui, depuis belle lurette, n'étaient plus ces signaux de fumée qui autrefois montaient se mêler aux nuages, sans nous livrer leurs secrets" (p. 14-15). 